\title{
REVOLUCIÓN, DESENCANTO Y CRÍTICA: LA NOVELA CRIMINAL CUBANA
}

\author{
Javier Sánchez Zapatero \\ Àlex Martín Escribà \\ Universidad de Salamanca
}

\begin{abstract}
RESUMEN: El artículo analiza la evolución del género criminal en la literatura cubana a lo largo del siglo XX. Para ello, establece un recorrido histórico analizando de qué forma los acontecimientos históricos han condicionado las características de la novela criminal cubana y la han dotado de identidad dentro del neopolicial latinoamericano.
\end{abstract}

PALABRAS CLAVE: Literatura cubana, género negro, neopolicial latinoamericano, Leonardo Padura, ideología, desencanto.

\section{REVOLUTION, DISAPPOINTMENT AND CRITICISM: THE CRIME FICTION IN CUBA}

\begin{abstract}
The paper studies the evolution of crime literature in Contemporary Cuban Literature. The paper analyzes how the historical events have determined the characteristics of the crime fiction in Cuba, providing it a identity inside the LatinAmerican neopolicial.

KEYWORDS: Cuban Literature, Crime Literature, Latin-American Neopolicial, Leonardo Padura, ideology, disenchantment.
\end{abstract}

\section{En los márgenes del neopolicial}

El término "neopolicial", muy utilizado en el discurso crítico y científico de las últimas décadas -en las que el interés por el estudio de las narrativas populares se ha incrementado notablemente-, hace referencia a la novela criminal compuesta en los países latinoamericanos. Popularizado en 1999 por Leonardo Padura en su 
artículo "Modernidad y posmodernidad: la novela policial en Iberoamérica", incluido en el número 84 de la revista Hispamérica, la terminología ya había sido utilizada con anterioridad por Paco Ignacio Taibo II -quien en 1990 la usó para referirse a su producción, y a la de otros autores mexicanos, en una entrevista- y por los responsables de la Revista de neopolicial iberoamericano Crimen y castigo, de la que se publicó un único número en 1995 (García Talaván 2011: 50). Aunque su consolidación en el ámbito académico y editorial no se produjo hasta la década de 1990, la realidad a la que alude data de los años comprendidos entre 1969 y 1976, en los que se publicaron narraciones como El complot mongol (Rafael Bernal 1969), Días de combate (Paco Ignacio Taibo II 1976), En el lugar de los hechos (Rafael Ramírez Heredia, 1976) o "La loca y el relato del crimen" (Ricardo Piglia 1975; cuento incluido en Nombre falso), paradigmáticos y pioneros ejemplos del "nuevo realismo" que trajo consigo la adecuación a la literatura iberoamericana de los paradigmas de la novela negra hard-boiled estadounidense de autores como Dashiell Hammett o Raymond Chandler, de la que tomaron "el lenguaje desacatado, la plasticidad de sus escenas y su amenidad, conseguida a través de la acción continua, los agudos diálogos y el reflejo veraz de los diferentes estratos sociales" (Noguerol 2005: 147-148).

A pesar de que los géneros narrativos son, por su condición de modelos teóricos a través de los que agrupar textos en función de sus rasgos, estructuras universales independientes de cualquier condicionante contextual, resulta evidente que algunas características literarias -fundamentalmente, temáticas y argumentales- están estrechamente vinculadas con el marco lingüístico, geográfico, cultural y social en el que se producen las obras. En consecuencia, el término "neo-policial" no solo hace referencia a la procedencia geográfica y cultural -manifestada en el lugar de nacimiento y formación de los autores, o en el espacio en el que se desarrollan las tramas de las novelas-, sino también y sobre todo al modo en que la presencia de una serie de elementos estilísticos y pragmáticos trascienden la uniformidad universal del género criminal, distinguiendo las propuestas provenientes de Latinoamérica de las de otras partes del mundo. Así, dentro de los parámetros de esta corriente habría que situar la obra narrativa de autores como los mexicanos Paco Ignacio Taibo II, Rafael Martínez Heredia y Élmer Mendoza; los argentinos Ricardo Piglia, Mempo Giardinelli, Raúl Argemí y Guillermo Saccomanno; los chilenos Luis Sepúlveda y Ramón Díaz-Eterovic; el peruano Santiago Roncagliolo; el guatemalteco Dante Liano; los brasileños Rubem Fonseca y Patricia Melo; o los cubanos Daniel Chavarría, Leonardo Padura y Lorenzo Lunar -significativos ejemplos de un listado en creciente evolución-. 
Las principales señas de identidad del neopolicial parecen residir en su carácter realista, su dimensión social y su capacidad para cuestionar de forma crítica el contexto circundante. De este modo, la intriga inherente al misterio de un caso criminal no esclarecido, más que ser el elemento central de la trama narrativa, termina por convertirse en un pretexto que sirve a los autores para proyectar una mirada sobre la realidad histórica. No en vano, como afirma uno de los personajes de la obra de Paco Ignacio Taibo II La vida misma (1987), en la novela criminal latinoamericana "lo que importa no son tanto los crímenes como el contexto" (1987: 170). De ahí que Noguerol haya señalado que para el neopolicial resulta prioritario "reflejar la realidad" (2006: 149), tal y como puede percibirse en la vocación costumbrista y crónica con la que los autores representan en sus obras la cotidianeidad del continente latinoamericano. El espacio que se suele mostrar se caracteriza por su elevado nivel de concreción, que lleva a incluir en las novelas referentes topográficos perfectamente reconocibles y detalladas descripciones de los paisajes -fundamentalmente urbanos- en las que se desarrollan las tramas. Además, es habitual que se aborden temáticas relacionadas con los principales focos de conflictividad de las sociedades.

Otra de las características definitorias del neopolicial es la mirada crítica y desencantada que los narradores acostumbran a proyectar sobre la realidad hispanoamericana. No en vano, la frustración es una de las contantes del desarrollo del género, puesto que, como ha afirmado Mempo Giardinelli, "en América Latina [...] casi nadie se fía del poder establecido, más bien se vive en constante sublevación frente a él" (2013: 224). Retratar las ciudades del continente no es, por tanto, un intento de dotar a las novelas de una identidad cultural, sino, más bien, una forma de mostrar los claroscuros de una sociedad dominada por la violencia, la desigualdad y la corrupción. De ahí que la dimensión social del género negro latinoamericano tenga siempre un tono eminentemente crítico y cuestionador con el que, además de denunciar las irregularidades y abusos que se cometen en la sociedad, se intenta demostrar cómo "el hombre indefenso sigue perdiendo la batalla contra el poder envilecido que organiza el mundo a su antojo" (Salinas 2007: 6). La desconfianza de la ciudadanía ante las instituciones se percibe, por ejemplo, en la escasa presencia de representantes de las fuerzas de seguridad estatales como protagonistas y, en consecuencia, en la constante utilización del personaje del detective privado. De hecho, son muchas las novelas en las que se exponen las malas prácticas de los cuerpos policiales, mostrando sus métodos violentos, sus corruptelas o su complicidad con algunos grupos de delincuencia organizada. Semejante denuncia no se limita a criticar la actitud de las fuerzas de seguridad, sino que tiene como objeto cuestionar al sistema político al que representan. 
Al desencanto de la mirada que los autores vierten sobre la realidad que les rodea contribuye la constatación de que "la violencia multifacética [...] se ha convertido, a lo largo del siglo XX, en uno de los factores específicos de Latinoamérica" (Jastrzebska 2011: 126), hasta el punto de constituirse en una de sus principales señas de identidad, presente incluso en la famosa dicotomía de "civilización y barbarie" con la que suele asociarse al continente. Aunque la violencia es inherente a todo el género negro y policiaco -que, no en vano, siempre parte de una transgresión del orden establecido-, su presencia en el neopolicial es determinante por su valor al servicio del retrato social que proyectan sus autores. Según Giardinelli, el neopolicial latinoamericano transmite la idea de que la violencia es "coyuntural" (2013: 229), ya que surge del mal funcionamiento de las instituciones y de la irresponsabilidad de la ciudadanía. Por tanto, su presencia en las novelas no solo contribuye al realismo con el que se quiere reflejar la realidad -puesto que la violencia está presente a través de manifestaciones concretas como las de la delincuencia organizada en México, el narcotráfico en Colombia o el favelismo en Brasil-, sino también y sobre todo a acentuar la frustración con la que los autores observan su contexto. La asociación entre la criminalidad y las ciudades -ya presente en la concepción de las urbes como "junglas de asfalto" de los escritores estadounidenses hard-boiled del primer cuarto de siglo- genera la sensación de que la violencia se desborda de forma incontrolada y de que, por lo tanto, no hay forma de ordenar ni de dar estabilidad a la vida en las sociedades latinoamericanas. De ahí que el neopolicial rechace el concepto de verdad unívoca y las explicaciones globales sobre el origen de la criminalidad: puede que las tramas novelescas terminen por resolverse, y que el culpable sea descubierto, pero el contexto que propicia -y provoca - la violencia en la sociedad jamás podrá solucionarse sin una transformación radical de las estructuras económicas y políticas. No en vano, la violencia en Latinoamérica se manifiesta, además de en los efectos que la delincuencia y la criminalidad tienen en las rutinas de la vida cotidiana, en la presencia de sistemas políticos dictatoriales y represivos durante todo el siglo XX. Ese pasado común, manifestado con especial vehemencia en Argentina, Brasil, Chile o Cuba, ha terminado por convertirse en otro de los nexos del neopolicial, en el que es habitual la utilización de la literatura como medio deslegitimador del relato histórico impulsado desde el poder. De este modo, la novela criminal latinoamericana ha conseguido sumar a su valor de crónica social el de crónica histórica, vertebrando un contradiscurso capaz de cuestionar al relato historiográfico oficial, tal y como el propio Díaz-Eterovic se ha encargado de señalar:

Las novelas policiacas escritas en Latinoamérica están protagonizadas por sobrevivientes de la historia política vivida en las últimas décadas y por resistentes al nuevo 
orden que se impone. No es una literatura complaciente y los autores que la desarrollamos somos unos eternos sospechosos, porque mediante nuestras historias ejercemos el molesto oficio de remover la mugre que se esconde bajo las alfombras, desnudando las injusticias que nos rodean, hablando de temas que se siempre van a incomodar a quienes detentan el poder (2004: 45).

No obstante, tal y como ha expuesto García Talaván, dado que "ni todos los países sufren la misma situación, ni todos los escritores siguen las pautas, la diversidad en el tratamiento de los temas y de las distintas estrategias narrativas es una de las características del neopolicial" (2011: 53). Es cierto que las novelas negras y policiacas latinoamericanas proyectan una análoga identidad geográfica y cultural, pero también lo es que la heterogeneidad del continente, y las distintas idiosincrasia cultural e historia de cada uno de los países que lo integran, hace que en cada una de las literaturas nacionales el género haya desarrollado sus propias señas de identidad.

\section{De los orígenes a la literatura ideologizada}

En el caso de Cuba, la configuración de la novela criminal ha estado condicionada por las circunstancias políticas y sociales que han jalonado su evolución histórica, que han dotado de una marcada identidad local a un género circunscrito por lo demás a los cánones del neopolicial. De hecho, no puede entenderse la literatura, ni ninguna otra manifestación cultural o artística cubana, sin prestar atención a la peculiaridad del país caribeño, en el que el siglo XX se ha desarrollado de forma diferente a todas las naciones de su entorno por el efecto de la Revolución de 1959 y la implantación del régimen comunista.

Aunque, en sentido estricto, no puede hablarse de novela criminal en Cuba hasta la segunda mitad del siglo XX, sí que pueden detectarse algunos rasgos del género en algunos títulos del periodo prerrevolucionario. Es el caso de, por ejemplo, Contrabando (1938), de Enrique Serpa, una obra centrada en la dimensión social del delito y en la recreación de la marginalidad de los ambientes urbanos de La Habana -en concreto, del mundillo marinero y las dificultades de sus trabajadores para vivir dignamente sin tener que recurrir a actividades clandestinas-. Su publicación en el contexto de la literatura cubana de la época ha de entenderse como consecuencia de la penetración y asimilación en la isla de la narrativa anglosajona -y, muy especialmente, estadounidense-, traducida en una proporción mucho mayor que en otros países hispanoamericanos. De hecho, la importancia de los modelos foráneos es también perceptible en las revistas de relatos policiacos 
Detective Mundial o Sombras; en algunos relatos de Lino Novás Calvo; en la novela colectiva Fantoches (1926); o en las novelas de Leonel López-Nussa El ojo de vidrio (1955) y El asesino de la rosa (1957), publicadas con un pseudónimo en inglés. La influencia extranjera conllevó la imitación de algunos de los más reconocibles rasgos temáticos, formales y estilísticos del género negro, $\mathrm{y}$, de forma especial, de la voluntad de reflejar de forma crítica los problemas de la realidad cotidiana, tal y como ha señalado Luis Rafael Hernández:

El latifundio azucarero, la penetración imperialista, la situación del campesino, el protagonismo de los hombres humildes, los ambientes gansteriles... irrumpen traídos por nuevas voces que van a signar la contemporización de las letras cubanas, gracias a las lecturas de Sherwood Anderson, William Faulkner, Ernest Hemingway, James Joyce y D.H. Lawrence, entre otros que innovan las técnicas narrativas (2007: 68).

El cambio global que supuso el triunfo de la Revolución afectó también, cómo no podía ser otra manera, a la creación artística, y por extensión a la novela criminal. Los dos principales condicionantes que el nuevo marco político y social impuso al género fueron, por un lado, la promoción de una literatura que difundiese un mensaje oficialista cuya ideología se correspondía con la del régimen y, por otro, la limitación de los modelos narrativos extranjeros a imitar debido al efecto de la prohibición de la censura. Ante semejante tesitura, durante las primeras décadas del castrismo apenas pueden encontrarse muestras del género. Una de las pocas excepciones a este yermo panorama fue Enigma para un domingo (1968), de Ignacio Cárdenas. La obra se acerca a algunos de los cánones de la narrativa negra estadounidense a través del relato de una investigación que lleva a cabo un detective privado que ha de moverse por los ambientes más corruptos y violentos de La Habana en la década de 1950 para resolver un caso que le implica personalmente, puesto que él es el principal sospechoso. Considerado habitualmente el iniciador del género criminal en Cuba, Cárdenas ha desarrollado su carrera literaria de forma intermitente. Después de Enigma para un domingo, que llegó a convertirse con el tiempo en una de las novelas cubanas más traducidas de todo el siglo XX, publicó Preludio para un asesinato (1981) y Con el rostro en la sombra (1981), así como diversos cuentos incluidos en antologías como Cuentos policiacos (1973) o Varios cuentos policiacos cubanos (1980).

El desarrollo de la novela criminal cubana tuvo lugar a partir de 1971, coincidiendo con la celebración del I Congreso de Educación y Cultura celebrado en La Habana, a través del que se consolidó la idea de que "el arte es un arma de la Revolución, un producto de la moral combativa de nuestro pueblo, un instrumento contra la penetración del enemigo". Siguiendo esos preceptos, ese mismo año se 
creó el "Premio Aniversario de la Revolución", convocado por la Dirección Política del Ministerio del Interior con la colaboración de la editorial Capitán San Luis -encargada de publicar las novelas ganadoras- y destinado a galardonar a la mejor muestra del género escrita y publicada en Cuba. Así, el impulso al neopolicial cubano vino dado desde las propias estructuras de poder, que alentaron la composición de un tipo de narrativa muy concreto, con una muy clara función ideológica y aleccionadora, tal y como ha expuesto Leonardo Padura:

La filiación revolucionaria y socialista del premio quedaba establecida desde las bases de la convocatoria del concurso, y, por tanto, traía como marca de nacimiento la función ideológica reafirmativa [...]: es decir, la exposición apologética de la ideología revolucionaria, la propaganda elemental y primaria, el elogio desembozado de los procedimientos revolucionarios (2000: 151).

Se produjo así la eclosión de lo que se llegó a denominar como "novela policial revolucionaria o de contraespionaje", basada en su carácter de instrumento ideológico al servicio del mensaje gubernamental y en su condición de ejemplaridad al reflejar las instituciones políticas, culturales y policiales de la isla. Se pretendía, en definitiva, que el género negro y policiaco representara la "moral intachable" de la sociedad cubana -y de forma especial de sus dirigentes-, insistiendo en lo que Fidel Castro llegó a denominar como "la acrisolada honestidad de nuestros combatientes", y contribuyera con ello a "disciplinar un nuevo sujeto revolucionario cubano" (López 2010: 671). Para ello, las novelas se basaron en la repetición de una serie de preceptos que con el paso del tiempo terminaron por convertirse en clichés argumentales fácilmente reconocibles:

Dos o más investigadores -nunca uno solo para evitar el individualismo capitalistason ayudados por representantes idealizados del pueblo -viejecita chismosa pero amable, trabajador valiente y comprometido- para luchar contra los enemigos contrarrevolucionarios que, con la complicidad de sus familiares en el extranjero, planean derrocar el régimen. Al final, la revolución triunfa y los malos fracasan en sus mezquinos intentos (Noguerol 2006: 156).

Obras como La ronda de los rubíes (1972) -de Armando Cristóbal Pérez-, La justicia por su mano (1973) -de José Lamadrid Vega-, El cuarto círculo (1979) -de Luis Rogelio Nogueras y Guillermo Rodríguez Rivera- o Viento norte (1980) -de Carmen González Hernández- son algunos de los ejemplos que más paradigmáticamente demuestran la supeditación de las aspiraciones estéticas a la instrumentación ideológica. En todas ellas se observa, dentro de su heterogeneidad argumental, cómo lo didáctico se impone a lo estilístico a través de la recurrencia de una serie de 
elementos como la explícita identificación del delincuente con el contrarrevolucionario o de la presentación del pueblo como auténtico "héroe colectivo" capaz de salvar a la sociedad cubana de las amenazas imperialistas y capitalistas.

La reiteración de los mismos y estereotipados modelos, así como su elevado nivel de maniqueísmo y su evidente instrumentalización política, ha de entenderse, además de cómo resultado del control del régimen sobre todas las producciones discursivas, como la lógica consecuencia del seguidismo a la explícita normativa que sobre las características que habían de seguir las novelas negras y policiacas elaboró el Ministerio del Interior cubano dentro de las reglas del "Premio Aniversario de la Revolución”. Así, se pretendía que la obra galardonada cumpliera con los siguientes requisitos:

1.- Mantiene los rasgos esenciales del género, pero apunta a un nuevo sentido de la defensa social: es legal lo que es justo; 2.- Es el resultado de una transformación radical en el contenido ideológico de la literatura policial producida en el capitalismo; 3.- Entra a fondo en el terreno de la lucha ideológica, dada su eficacia como arma concienciadora; 4.- No desdeña la función de entretener, pero se propone una labor educativa al ahondar en las causas sociales y sociológicas del delito; 5.- Es la única realmente policial, pues en ella por primera vez la policía ocupa un lugar protagónico. El investigador es un hombre común, sin genialidades; 6.- Muestra un fuerte sentido colectivo en el enfrentamiento al delito, con el apoyo de la población fundamentalmente a través de los Comités de Defensa de la Revolución; y 7.- Enseña cómo en la sociedad cubana desaparecen las diferencias entre el delito común y el contrarrevolucionario.

A estas características se había de sumar el castigo al criminal -contrarrevolucionario-, que jamás podía quedar impune, puesto que cualquier atentado contra los intereses del pueblo había de ser castigado en una sociedad que repudia y combate el delito como una lacra del pasado capitalista. Para Lorenzo Lunar, las directrices impuestas por las bases del concurso se basaban en la obligación de las novelas de "reflejar la actividad de los combatientes del Ministerio del Interior en el enfrentamiento a la delincuencia y a la contrarrevolución” (2011: 312). Según Jiménez (1980: 96), en esa pugna entre los representantes y los enemigos se mostraba cómo los elementos que disentían del orden utópico revolucionario eran "actos delictivos a eliminar: robos, homosexualidad, intentos de fuga, promiscuidad, vagancia, ausentismo laboral, superchería..., [...] 'delitos' [que] conformaban el afuera de la revolución como residuos de un pasado capitalista”.

Las imposiciones del régimen provocaron que la narrativa criminal cubana se situase más cerca de los modelos de intriga e misterio de finales del siglo XIX que de los del realismo crítico de las décadas de 1920 y 1930. La estructura de las na- 
rraciones policiacas clásicas, en las que el orden establecido era subvertido por una acción criminal para ser después repuesto por la acción de un investigador privado - a menudo dotado de unas ilimitadas capacidades racionales- se adaptaron al peculiar caso cubano y a la función educativa con la que parecían concebidas las obras literarias: no solo era necesario que el culpable fuese castigado, sino también que el sistema político y social cubano no se viese alterado por su acción, demostrando así la fortaleza de la Revolución. A la proliferación de narraciones centradas en la resolución del misterio contribuyó la creación de la colección "Dragón" de la editorial Arte y Literatura, que, dirigida por Óscar Hurtado, fue pionera en la edición en la isla de traducciones de narrativas populares anglosajonas después de la Revolución, contribuyendo a la difusión en la isla de autores como Arthur Conan Doyle, S. S. Van Dine o Agatha Christie.

De este modo, en la década de 1970 se produjo una paradójica situación, que evidencia de forma paradigmática la particularidad de las letras cubanas y su aislamiento del resto de Latinoamérica. Mientras que en otros países del continente comenzaron a aparecer escritores -Rafael Bernal, Jorge Ibargüiengoitia, Rafal Ramírez Heredia y Paco Ignacio Taibo II en México; Rubem Fonseca en Brasil; Ricardo Piglia en Argentina- que utilizaban la novela criminal para radiografiar y cuestionar el comportamiento de las sociedades y las formas de gestionar el poder de los gobiernos, en Cuba el género se convirtió en un instrumento al servicio del férreo control ideológico político y cultural del régimen, sin atisbo alguno de crítica ni oposición a lo establecido. Así, según Luis Rogelio Nogueras (1982: 31), la narrativa criminal cubana compuesta a partir de 1971 adquiere unas peculiaridades que la distinguen de las otras propuestas del género desarrolladas en el resto del continente:

\begin{abstract}
En primer lugar, el delincuente se enfrenta [...] al estado revolucionario, al pueblo en el poder. En segundo lugar, el investigador no es un aficionado, sino un verdadero policía, que representa a ese mismo pueblo. En tercer lugar, y como lógica consecuencia de lo anterior, ese investigador recibe la colaboración de las organizaciones populares de la Revolución [...]. Y en cuarto lugar, no se trata en puridad de un investigador (aunque exista el investigador-jefe como figura central), sino de un equipo, que realiza su trabajo de manera coordinada y científica.
\end{abstract}

La utilización de las novelas como meros instrumentos de propaganda ideológica se mantuvo vigente hasta mediados de la década de 1980. Aunque algunas novelas -como No es tiempo para ceremonias (1974), de Rodolfo Pérez Valero, o Joy (1977), de Daniel Chavarría, uruguayo de nacimiento, pero instalado en la isla desde 1969-, lograron trascender la supeditación a los preceptos del régimen y, a pesar de mantener fidelidad al monolitismo ideológico, superar el maniqueísmo y 
la estereotipación de la mayoría de obras, lo cierto es que en las alrededor de cincuenta muestras de género criminal que se publicaron en Cuba entre 1971 y 1986 apenas hubo títulos destinados a perdurar. A pesar de la popularidad de las novelas -que en algunos casos llegaron a superar los 100.000 ejemplares vendidos y que, en casi todos los casos, contaron con el beneplácito de los lectores-, el neopolicial cubano, extremadamente condicionado por su interpretación triunfalista de la Revolución, terminó por entrar en una espiral de agotamiento y falta de evolución, tal y como explicó Padura:

La característica fundamental de la tradicional novela policial cubana que se escribió en $\operatorname{los} 70, \operatorname{los} 80$, era su carácter excesivamente político. Era una literatura muy politizada que trataba de reflejar en sus incapacidades -más que en sus capacidades- los problemas de una sociedad que se resolvía favorablemente siempre gracias a la intervención de una policía muy eficiente, de unos órganos de investigación muy conscientes de su misión, de su importancia. Esa literatura se politizó tanto que la política terminó por devorarla aunque este peligro se vio desde el principio (Wieser 2005).

La reiteración de modelos altamente politizados y basados en la muestra de los esfuerzos de los servicios de Seguridad del Estado Cubano para preservar el bienestar de la sociedad y mantenerla a salvo de la amenaza exterior americana y de, en general, todos los "enemigos de la Revolución" provocaron la falta de desarrollo del género. A falta de nuevas propuestas que, alejadas de los cánones marcados por las políticas culturales y editoriales imperantes, pudieran subvertir tendencias como las propugnadas desde el régimen, el género en Cuba entró en un estado de decadencia que, además de repetir fórmulas y temas, concebía la literatura como un mero instrumento ideológico más. El agotamiento del modelo es susceptible de ser percibido en novelas como las compuestas en colaboración por Daniel Chavarría y Justo Vasco -Completo Camagüey (1983) y Primero muerto (1986)-, en las que se abandona el oficialismo para ofrecer una mirada poco complaciente con la realidad.

La evolución de los acontecimientos históricos a partir de 1989, con la caída del Muro de Berlín, el desmantelamiento de la Unión Soviética y la situación general de crisis en la que desde entonces vive Cuba -marcada, grosso modo, por el cuestionamiento del poder gubernamental, la pérdida de poder adquisitivo de la población, el empobrecimiento generalizado de la sociedad y la proliferación de actividades vinculadas con el tráfico de drogas o la prostitución- acentuaron la decadencia de la ideologizada y maniquea fórmula narrativa bajo la que se había presentado la novela negra y policiaca en la isla. 


\title{
3. Crónica y desencanto. El caso de Leonardo Padura
}

El panorama expuesto se alteró sustancialmente en la década de los noventa, cuando la novela criminal cubana experimentó una modificación tanto conceptual como formal. El principal cambio residió en la voluntad de los autores de ejercer de cronistas a través de sus novelas, aprovechando las estructuras temáticas y formales del género sin someterse a ningún tipo de condicionante ideológico más allá del representando por la censura de la isla.

El autor de que forma más paradigmática demuestra este nuevo valor de la novela criminal cubana es Leonardo Padura, creador del investigador Mario Conde, protagonista hasta la fecha de ocho novelas. Escritor y periodista durante años en medios como La Gaceta de Cuba y El Caimán Barbudo, Padura realiza a través de sus obras un análisis exhaustivo de la situación política y social cubana, exponiendo realidades vetadas por los medios oficiales -desde el exilio, que en sus novelas se interpreta desde claves más personales que políticas, hasta la presencia masiva de la delincuencia y la corrupción-. De este modo, su concepción del género es análoga a la de otros autores latinoamericanos que, como Taibo II, DíazEterovic o Giardinelli, muestran las contradicciones y claroscuros de sus países a través de un realismo tan crítico como desencantado:

\begin{abstract}
No existe en Cuba un periodismo que refleje todas las contradicciones de la realidad. El periodismo cubano que se hace dentro de Cuba es un periodismo oficial porque los periódicos pertenecen al estado. Muchas veces, el que se hace fuera de Cuba es un periodismo que trata de buscar lo peor de la sociedad cubana como una manera de promover un estado de ánimo, una idea diferente de Cuba. Y son dos polos que siempre están en antagonismo. Yo quería hablar, desde una realidad que conozco muy bien y desde una perspectiva interior, de este mundo cubano con una visión [...] personal pero que también fuera en muchos sentidos la visión de mi generación, de las frustraciones, las esperanzas, los desencantos de mi generación. Por eso, de novela policial hay un por ciento evidente en estos libros, pero creo que hay mucho más que novela policial. Por eso, yo no me siento un escritor de novela policial aunque haya escrito novelas policiales, [...] porque mis intereses realmente nunca están en quién mató a quién, sino en por qué alguien mató a otro, por qué alguien robó, cómo lo hizo. El quién es lo menos importante, el cómo y el porqué son los que más me interesan (Wieser, 2005).
\end{abstract}

Su interpretación de la novela como periodismo capaz de retratar las sociedades contemporáneas y denunciar las principales lacras que las afectan está presente en toda su obra. En la serie policiaca protagonizada por Mario Conde -tanto en la tetralogía "Las cuatro estaciones" (compuesta por Pasado perfecto [1991], Vientos de 
cuaresma [1994], Máscaras [1997] y Paisaje de otoño [1998]) como en La cola de la serpiente (1998), ;Adiós, Hemingway! (2001), La neblina del ayer (2005) y Herejes (2013) - se observa su intención de convertirse en testigo crítico y escéptico de la realidad cubana, así como en cronista de un tiempo y un espacio concretos. En sus novelas, "el autor describe la sociedad cubana como una sociedad en la que las cosas no son lo que parecen: hay lo que podríamos llamar como una 'versión oficial' de la sociedad cubana que no se corresponde con la realidad que él denuncia" (Martínez 2012: 257). Padura refleja en sus obras problemas concretos de la sociedad cubana y denuncia sin tapujos asuntos de corrupción en el seno del gobierno y del Partido Comunista, problemas de inseguridad ciudadana, situaciones de miseria y desamparo, etc. Lo hace, además, desde una posición ideológica muy determinada, que vincula al autor con otros narradores cubanos como Abilio Estévez o Arturo Arando: como ha señalado Fornet, todos ellos forman parte de la "generación del desencanto", y "todo desencanto presupone la extinción de la fe en la utopía” (2001: 45). Sin embargo, lejos de vincularse exclusivamente con la realidad histórica y con la tradición literaria cubanas, la obra narrativa de Padura parece asumir también como referentes a autores europeos de novela negra. En ese sentido, resulta imprescindible aludir a la "serie Carvalho" de Manuel Vázquez Montalbán al analizar la narrativa negra de Padura, no solo por el hecho de que el detective creado por el escritor barcelonés sea también un "ojo crítico" de la historia reciente española, sino también y sobre todo por la importancia que en sus obras adquieren la memoria y el desencanto.

A diferencia de las novelas de narradores más jóvenes -que observan la decadencia de la isla desde una posición crítica que no parte de una confianza previa en las premisas de la Revolución-, las obras protagonizadas por el Conde no pueden analizarse sin tener en cuenta su permanente dialéctica entre el pasado -la memoria- y el presente -el desengaño-. El protagonista de Padura parece vivir en una continua lucha entre una sociedad que le disgusta y un tiempo pretérito el que se recuerda feliz soñando por unos ideales que hoy se le antojan imposibles. De hecho, Mario Conde se muestra en las novelas como un ser desencantado, frustrado ante el desarrollo de la Revolución y ante el estado de la Cuba de la década de los noventa y, sobre todo, desencantado por el fracaso de todos los ideales revolucionarios en los que creyó de joven. Su desengaño no solo está relacionado con el devenir de los acontecimientos sociales, políticos e históricos, sino también con su propia evolución personal. A Conde le hubiera gustado ser escritor y, sin embargo, tiene que conformarse con ser primero inspector de policía, y después vendedor de libros. Asimismo, todo lo que rodeó sus años de juventud, llenos de idealismo, fe en el futuro y confianza en el régimen, parece haberse venido abajo como un 
castillo de naipes. Quizá el personaje que de forma más paradigmática evidencia ese derrumbe sea el del "Flaco" Carlos, amigo íntimo del protagonista desde la infancia que, en plena década de los noventa, ya hace mucho que dejó de ser flaco y arrastra su sobrepeso en la silla de ruedas en la que permanece postrado por una herida en la guerra de Angola. Como Cuba, el personaje es el símbolo de lo que pudo ser y no fue.

La importancia de la memoria en las siete novelas se vertebra a través de diversos procedimientos. En primer lugar, de forma casi anecdótica, el pasado ya aparece en el aparato paratextual de las ocho obras -condicionando, por tanto, las expectativas lectoras- a través de su presencia en el título, tal y como evidencian Pasado perfecto, La neblina del ayer o ;Adiós, Hemingway!, en la que se hace referencia a un símbolo cultural perfectamente identificado con el pasado cubano.

En segundo lugar, la rememoración adquiere importancia prácticamente en todas las tramas criminales que vertebran las obras. Si toda novela negra implica una vuelta al pasado, pues toda pesquisa está destinada a reconstruir lo que ocurrió, mucho más intensa será esa implicación en las obras en la que la reconstrucción no se limita al pasado inmediato, sino a uno mucho más remoto. Así, por ejemplo, novelas de Padura como La neblina del ayer, ¡Adiós, Hemingway! o Herejes narran investigaciones que, desde el presente, sirven para solucionar crímenes acaecidos varias décadas atrás - el misterio de Violeta del Rey en el primer caso, la aparición de un cadáver en Finca Vigía en el segundo y la desaparición de un cuadro en los albores de la II Guerra Mundial en el tercero-. En el pasado están también las claves que permiten, también en La neblina del ayer, explicar la muerte del personaje de Dionisio. La memoria y la búsqueda de lo sucedido años atrás se convierten así en elementos con los que el Conde ha de trabajar para solucionar los casos, algo que afecta a la estructura narrativa de las novelas, cuyo orden se ve alterado por la presencia de procedimientos analepticos o por la inclusión de discursos periodísticos o epistolares del pasado. Pero probablemente la vuelta al pasado más importante que el protagonista ha de realizar es la que afecta a su propia peripecia personal, la que le obliga a enfrentarse con quien un día fue. En Pasado perfecto o Vientos de Cuaresma, el investigador ha de resolver sendos casos que le obligan a revolver en las entretelas de su memoria. En la primera novela, ha de investigar la desaparición de un importante cargo del Ministerio de Industrias cubano a quien el Conde conoció años atrás: fue compañero suyo en el Preuniversitario y estaba casado con Tamara, su amor de juventud. Inevitablemente, sus pesquisas le llevarán a recordar el tiempo pasado en el que conoció al objeto de su búsqueda y a retomar el contacto con Tamara. El caso, en consecuencia, terminará por convertirse "un 
imán que revolvía nostalgias lejanas, días que muchas veces quiso olvidar, melancolías sepultadas" (Padura 2009: 27). No en vano, "la ruta de los recuerdos para el Conde siempre terminaba en la melancolía” (Padura 2009: 189), porque mirar atrás lleva consigo la decepción de darse cuenta del fracaso de sus sueños de juventud: desde los más personales, vinculados con sus deseos de ser escritor o de vivir junto a Tamara, hasta los más colectivos, identificados con el fracaso del ideal revolucionario. En Vientos de Cuaresma, que presenta una estructura muy similar a $\mathrm{Pa}$ sado perfecto, el investigador ha de encontrar el culpable del asesinato de una profesora que trabajaba, precisamente, en el mismo instituto al que él acudió -el "Pre" del Víbora-. Al igual que el caso anterior, la vuelta -literal, en este caso- al espacio donde pasó gran parte de su juventud trae consigo la melancolía del Conde. No solo observa la decadencia -física y moral- del instituto -símbolo, en definitiva, de la decadencia de La Habana, que según el personaje "se había ido ennegreciendo con el tiempo" (Padura 2007: 218)-, sino también y sobre todo la suya propia. Convertido en policía, el Conde no se reconoce ni a sí mismo ni a sus amigos en los jóvenes que un día fueron.

En tercer lugar, el pasado está muy presente en la descripción y la evolución del personaje de Mario Conde, a quien, de hecho, se le describe como "nostálgico empedernido" y un "cabrón recordador" (Padura 2005: 102). Para él, la memoria se convierte en una especie de válvula de escape que le permite huir de un contexto en el que ya no se encuentra feliz, como se muestra en este pasaje de Pasado perfecto:

¿Qué has hecho con tu vida, Mario Conde?, se preguntó como cada día, y como cada día quiso darle marcha atrás a la máquina del tiempo y uno a uno desfacer sus propios entuertos, sus engaños y excesos, sus iras y sus odios, desnudarse de su existencia equivocada y encontrar el punto preciso donde pudiera encontrar de nuevo (Padura 2009: 141).

Por eso recordar es casi siempre para el Conde entrar en contacto con un mundo idealizado donde se entremezclan las imágenes de su abuelo llevándole a ver peleas de gallos con las de su infantil enamoramiento de su profesora de alemán, las de los primeros amores con las de la fe inquebrantable en la Revolución... La comparación de ese pasado con el presente trae consigo una inevitable sensación de desencanto. Por eso la memoria funciona en las novelas del mismo modo que las comidas en las que Josefina -la madre del "Flaco" Carlos- utiliza su imaginación culinaria para escapar de las carencias del racionamiento, como una forma de huir de un presente que le oprime y le entristece. Y por eso la evolución del personaje es la que es: el hecho de que después de su cuarta novela Conde decida dejar la policía y convertirse en vendedor de libros es una crítica a un sistema en el que 
ya no cree -puesto que él, que llega a decir que se hizo policía para "evitar que los hijos de puta hagan cosas malas impunemente" (Padura 2009: 102), se da cuenta de que su trabajo ya no sirve para encarcelar a los culpables-, pero también una forma de reencontrarse con el sueño literario de su juventud.

Y, en cuarto y último lugar, la memoria no puede disociarse de la ideología de las novelas y, sobre todo, de la crítica que proyectan a la realidad socio-política cubana. El cuestionamiento de las estructuras oficiales del régimen no solo se lleva a cabo a través de la denuncia de la persecución de los homosexuales -tema central de Máscaras-, de la exposición de los traumas generados por la guerra de Angola -presente en toda la serie narrativa gracias a la presencia del personaje del "Flaco" Carlos- o de la corrupción de dirigentes revolucionarios -subyacente a todas las novelas, pero especialmente explícita en Vientos de Cuaresma y en Pasado perfecto, en la que se llega a aludir a "colegas de veinte años traicionándose enconadamente, viejos policías intachables descubiertos como malandrines consuetudinarios, casos sepultados bajo cantidades insospechadas de billetes, favores consentidos a cambios de las más disímiles mercancías" (Padura 2009: 31)-, sino también y sobre todo en la muestra del desengaño y de la frustración con la que muchos cubanos como el Conde observan lo sucedido en la isla. Así, la disidencia crítica de Padura se basa en su capacidad para vertebrar un mensaje ausente de los filtros oficiales del régimen, tal y como se expone en La neblina del ayer al reflexionar sobre la decadencia moral que parece azotar al país:

Cada vez que hay un baile público o una pelea de perros, o cuanto están aburridos, se drogan con lo que encuentran y después están que se matan entre ellos: pero se matan de verdad... Y sacan el dinero de cualquier parte, pero casi siempre lo consiguen robando, puteando o vendiendo drogas de otros. O se les ocurre meterse en una casa robar cualquier cosa, y en el camino pueden dejar dos o tres muertos. Los periódicos no hablan de estas cosas... (Padura 2005: 105).

El mismo tono crítico y desencantado que caracteriza las novelas de Leonardo Padura puede detectarse en los acercamientos a la literatura policial que a partir de la década de 1990 han realizado otros autores de su generación, como Justo Vasco - que lanzó un furibundo ataque al régimen a través de la denuncia de la decadencia moral y física de la isla en El guardián de las esencias (2007), su obra póstuma- o José Latour -autor de dilatada trayectoria que en obras como Mundos sucios (1999) o El tonto (2002) ha abordado la corrupción y la decadencia del sistema, hasta el punto de ser tildado por el régimen de "autor contrarrevolucionario"-. Según Valle, Vasco y Latour comparten con Padura el tratamiento de "la marginalización de la sociedad a escala nacional, el desvelamiento de la corrupción 
dentro de un stablishment que se niega a aceptar tales corrupciones por absurdas ideas de barricada, y la entronización en el pensamiento social de la ética de la marginalidad como única forma de supervivencia social" (2007: 100).

\section{Nuevas voces: disidencia y crítica}

La condición de cronista que reflejan las obras protagonizadas por Mario Conde, así como su crítica visión de la sociedad, también está presente en las novelas de escritores cubanos vinculados al género como Amir Valle o Lorenzo Lunar. Pertenecientes a una generación más joven que la de Padura, estos narradores se han aproximado al género criminal desde diversos puntos de vista y perspectivas para mostrar su interpretación, cuestionadora y nada complaciente con el poder -y carente de premisas esperanzadoras sobre el futuro de la Revolución-, de la realidad cubana. Las novelas de Valle y Lunar son muestras canónicas de género -ambos, de hecho, han creado sagas, protagonizadas por Alain Bec en el caso del primero y por Leo Martín en el del segundo- en las que se utiliza el recurso argumental de la investigación para indagar en algunos aspectos de la política y la sociedad cubanas contemporáneas. Los protagonistas de las novelas de ambos autores se convierten en "ojos críticos" que, gracias a la movilidad que demandan sus acciones en sus pesquisas, entran en contacto con diversas realidades de la isla. Más allá de su permanente mirada inquisidora, que contrasta con la visión oficialista y triunfante que suele verterse desde el régimen, lo que destaca de sus obras es su capacidad para abordar temas impensables en la narrativa cubana anterior a la década de 1990: el turismo homosexual -Últimas noticias del infierno (2005)-, el tráfico ilegal de personas hacia Estados Unidos -Santuario de sombras (2006)o la presencia de redes de narcótrafico -Largas noches con Flavia (2008)- en el caso de Valle; el hambre y la marginalidad -Que en vez de infierno encuentres gloria (2003)-, la prostitución -Usted es la culpable (2006) - o la violencia sobre los turistas -Mundos de sombras (2012) - en el caso de Lunar. Junto a la denuncia de temas concretos $-\mathrm{y}$, sobre todo, a la exposición de un gobierno incapaz de atajar la violencia y la delincuencia en la isla-, en las novelas de ambos autores se dibuja un fresco cotidiano que refleja algunas de las contradicciones que definen el presente cubano desde la década de 1990. Lo que muestran Valle y Lunar no es más que una radiografía de un presente caracterizado por una sociedad dividida entre quienes tienen acceso al peso convertible y quienes han de seguir utilizando la devaluada moneda nacional; entre quienes pueden tratar con los turistas -y con sus divisas- y quienes están condenados a las carencias; entre las esferas de poder -en ocasiones corruptas- y los ámbitos de la marginalidad; entre quienes se ven obli- 
gados a emigrar y quienes para subsistir recurren al narcotráfico, la prostitución o el mercado negro...

La Habana, escenario de casi todas las obras mencionadas y símbolo evidente de Cuba tanto por su condición capitalina como por su valor icónico, se muestra como un espacio degradado marcado por la muerte, la inseguridad y la falta de medios. Frente a la triunfalista visión de la Revolución y el régimen efectuada desde el poder, escritores como Valle o Lunar demuestran la capacidad de "resistencia" que en ocasiones la literatura puede adquirir al iluminar aspectos de la sociedad habitualmente oscurecidos, dar voz a los que habitualmente quedan al margen de la configuración de la realidad o, simplemente, contrarrestar las visiones de la sociedad propagadas desde los medios de difusión masivos.

Otros escritores que en ocasiones han sido catalogados por la crítica como exponentes del género negro cubano contemporáneo son Ronaldo Ménendez o Ena Lucía Portela, representantes de la denominada generación de "novísimos" o "narradores post-revolucionarios" a la que también se adscriben Karla Suárez o Wendy Guerra. El primero -autor de Las bestias (2006) y Río Quibú (2008), primera y segunda parte de una trilogía aún inconclusa- carece del valor referencial que tienen Valle o Lunar. En su caso, el realismo, la intención crónica y la concreción de unas coordenadas espacio-temporales muy marcadas que caracterizan las obras de estos son sustituidos por una visión grotesca, casi esperpéntica, de la realidad cubana. Menéndez denuncia con fiereza la violencia ejercida desde el poder en la isla, así como la pésima situación en la que viven sus habitantes. Sin referirse a problemáticas concretas como sus antecesores, el escritor muestra una lamentable visión de la isla basada en lo que podría denominarse como el "absurdo cotidiano": todo, desde que un profesor universitario críe un cerdo en su bañera para poder subsistir o que se practique canibalismo, es posible en la Cuba que construyen las novelas del autor. Evidentemente, bajo semejante visión subyace la situación de la isla en la década de 1990, cuando, debido a la fortísima crisis económica provocada por el desmantelamiento de la Unión Soviética, comenzaron a escasear las materias básicas y se procedió al racionamiento de algunos alimentos básicos. La interpretación grotesca y crítica de la realidad de las novelas de Menéndez está filtrada por dos referentes claros: por un lado, el "realismo sucio" -que le emparenta con Pedro Juan Gutiérrez, uno de los más significativos narradores cubanos de los últimos años-; por otro, el género criminal, interpretado de forma muy personal y nada canónica, y que, de una u otra forma, sustenta la arquitectura narrativa de todas sus obras, en las que se denuncia cómo la asfixiante opresión del contexto violento condiciona el comportamiento de los personajes. 
La misma interpretación laxa del género que presentan las novelas de Ronaldo Menéndez está presente en Ena Lucía Portela, a quien algunos sectores de la crítica y la industria editorial han vinculado con el neopolicial, fundamentalmente por Cien botellas en la pared (2002). Es cierto que la novela, ambientada en el habanero barrio del Vedado, refleja un fresco de violencia análogo al de muchas muestras de género, pero también lo es que Portela subraya por encima de todo la dimensión social de la novela, en la que se intenta mostrar el día a día que se vive en la capital cubana en los duros años del Período Especial.

\section{Conclusión: entre lo nacional y lo continental}

De lo expuesto en las páginas precedentes puede concluirse la univocidad de la novela criminal cubana. A pesar de imbricarse en la tradición continental del neopolicial, y de compartir por ello una serie de características temáticas y formales con las muestras procedentes de otros países latinoamericanos, los autores cubanos que se han acercado al género lo han hecho condicionados por las peculiares características que han jalonado la evolución social y política de la isla. El desarrollo de los acontecimientos históricos, marcado por la Revolución de 1959 y las diferentes fases por las que desde entonces ha ido pasado el régimen comunista -condicionadas por hitos como el Primer Congreso Nacional de Educación y Cultura de 1971, la caída del Muro de Berlín o el Período Especial-, ha ido configurando así una tradición de novela criminal dentro de la literatura cubana.

\section{Bibliografía}

DÍAZ-ETEROVIC, R. (2004). "Novela policial en Latinoamérica" en El neopolicial latinoamericano: de los sospechosos de siempre a los crímenes de estado (Ed. A. Bisama). Valparaíso: Puntángeles, pp. 43-50.

FORNET, J. (2001). "La narrativa cubana entre la utopía y el desencanto". La Gaceta de Cuba 5: 38-45.

GARCÍA TALAVÁN, P. (2011). "Transgenericidad y cultura del desencanto: el neopolicial brasileño". Letral 7: 49-58.

GIARDINELLI, M. (2013). El género negro. Orígenes y evolución de la literatura policial y su influencia en América Latina. Buenos Aires: Capital Intelectual.

JASTRZEBSKA, A. (2011). "Entre negro, rosa y amarillo: ¿lo 'multicolor' de la novela de violencia hispanoamericana constituye un género particular?" en Género negro para el siglo XXI (Eds. J. Sánchez Zapatero y À. Martín Escribà). Barcelona: Laertes, pp. 125-134. 
JIMÉNEZ, O. (1980). "Un nuevo fenómeno de la literatura cubana: la novela policial". Círculo: Publicación del Círculo de Cultura Panamericano 9: 93-100.

LÓPEZ, M. (2010). "Espías y detectives calibánicos: marcando y difuminando los límites de la nación cubana revolucionaria". Revista Iberoamericana 232-233: 671-693.

LUNAR, L. (2011). "Estética y estática de la novela policial cubana" en Retóricas del crimen (Ed. E. de Rosso). Jaén: Alcalá Grupo Editorial, pp. 303-320.

MARTÍNEZ, L. R. (2007). "La narrativa cubana: del policiaco a la literatura negra" en Informe confidencial. La figura del detective en el género negro (Eds. À. Martín Escribà y J. Sánchez Zapatero). Valladolid: Difácil, pp. 67-76.

MARTÍNEZ, P. (2011). "Leonardo Padura, entre la realidad y la ficción" en El género negro: el fin de la frontera (Eds. Javier Sánchez Zapatero y Àlex Martín Escribà). Santiago de Compostela: Andavira, pp. 255-260.

NOGUERAS, L. R. (1982). Por la novela policial. La Habana: Unión.

NOGUEROL, F. (2006). "Neopolicial latinoamericano: el triunfo del asesino" en Manuscrito criminal. Reflexiones sobre novela y cine negro (Eds. Àlex Martín Escribà y Javier Sánchez Zapatero). Salamanca: Cervantes, pp. 141-158.

PADURA, L. (1999). "Modernidad y posmodernidad: la novela policial en Iberoamérica". Hispamérica 84: 37-50.

PADURA, L. (2000). Modernidad, posmodernidad y novela policiaca. La Habana: Unión.

PADURA, L. (2005). La neblina del ayer. Barcelona: Tusquets.

PADURA, L. (2007). Vientos de Cuaresma. Barcelona: Tusquets.

PADURA, L. (2009). Pasado perfecto. Barcelona: Tusquets.

SALINAS, A. (2007). "Novela negra y memoria en América Latina". Poligramas 27: 2-13.

TAIBO II, P. I. (1987). La vida misma. Gijón: Júcar.

VALLE, A. (2007). "Marginalidad y ética de la marginalidad en la nueva ciudad narrada por la novela negra latinoamericana". Anales de Literatura Hispanoamericana 36: 49-58.

WIESER, D. (2005). "Leonardo Padura: Siempre me he visto como uno más de los autores cubanos". Espéculo $29<\mathrm{http}: / /$ www.ucm.es/info/especulo/numero29/ Padura.html> (Acceso 24 octubre 2013). 